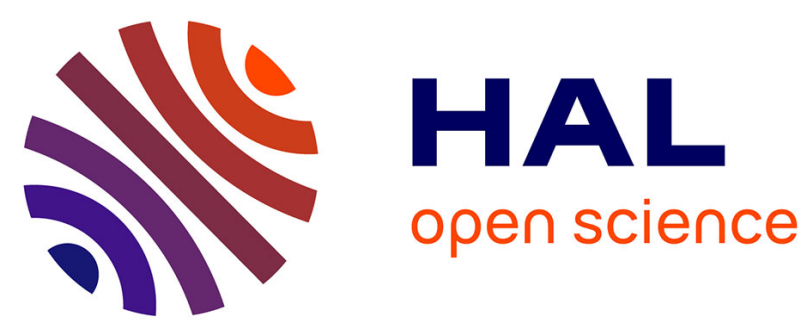

\title{
Screening of potential uranium protein targets in fish ovaries after chronic waterborne exposure: differences and similarities between roach and zebrafish.
}

\author{
Sandrine Frelon, Olivier Simon, Yvan Eb-Levadoux, Sandra Mounicou
}

\section{To cite this version:}

Sandrine Frelon, Olivier Simon, Yvan Eb-Levadoux, Sandra Mounicou. Screening of potential uranium protein targets in fish ovaries after chronic waterborne exposure: differences and similarities between roach and zebrafish.. Journal of Environmental Radioactivity, 2020, 222, pp.106365. 10.1016/j.jenvrad.2020.106365 . hal-02920583

\section{HAL Id: hal-02920583 \\ https://hal.science/hal-02920583}

Submitted on 1 Sep 2020

HAL is a multi-disciplinary open access archive for the deposit and dissemination of scientific research documents, whether they are published or not. The documents may come from teaching and research institutions in France or abroad, or from public or private research centers.
L'archive ouverte pluridisciplinaire HAL, est destinée au dépôt et à la diffusion de documents scientifiques de niveau recherche, publiés ou non, émanant des établissements d'enseignement et de recherche français ou étrangers, des laboratoires publics ou privés.

\section{(1) (1) $\$$}

Distributed under a Creative Commons Attribution - NonCommercial - NoDerivatives 44.0 
Fiche bibliographique

№ dossier : PUB20200303

Référence :

FRELON Sandrine, SIMON Olivier, EB-LEVADOUX Yvan, MOUNICOU Sandra

Screening of potential uranium protein targets in fish ovaries after chronic waterborne exposure: differences and similarities between roach and zebrafish.

J. Environ. Radioact., 222, (Elsevier 2020) 106365 | 10.1016/j.jenvrad.2020.106365 (ACL)

Auteurs dans l'ordre de la publication:

1, FRELON, Sandrine, REFERENT, CORRESPONDING AUTHOR

Institut de radioprotection et sûreté nucléaire, PSE-ENVISRTE/LECO, Cadarache, France

2, SIMON, Olivier

Institut de radioprotection et sûreté nucléaire, PSE-ENVISRTE/LECO, Cadarache, France

3, EB-LEVADOUX, Yvan

Institut de Radioprotection et de Sûreté Nucléaire, PSE-ENV/SRTE/LECO, France

4, MOUNICOU, Sandra, CORRESPONDING AUTHOR

CNRS/Univ Pau \& Pays Adour ES UPPA, Institut des sciences analytiques et de physico-chimie pour

l'environnement et les matériaux, UMR5254, Pau, France

Type : Publication écrite

Titre : Screening of potential uranium protein targets in fish ovaries after chronic waterborne exposure:

differences and similarities between roach and zebrafish.

Résumé d'auteur : Concentration of uranium (U), a naturally encountered radioactive element in earth's crust, can be enhanced in freshwater ecosystems ( $\mu$ g.L-1 - mg.L-1) due to various anthropogenic activities. The consequent aquatic organism exposure to $U$ leads to its accumulation in all organs, particularly in the gonad, and in subcellular fractions (mainly the cytosol); then it is known to affect fish at several biological levels, and more particularly, at a reproduction endpoint, with a decrease in the total number of eggs, spawn events and larvae survival. The understanding of $U$ reprotoxicity requires the fine knowledge of its speciation at molecular level, i.e., its interaction with cytosolic biomolecules. In this study, we focus on the U-protein interactions in gonads. A nondenaturating extraction protocol combined with size exclusion chromatography (SEC) allowed the separation of metal-protein complexes in ovaries of U-contaminated wild roaches before their elemental detection (ICP MS). This enables unprecedented information to be obtained about $U$ distribution in ovaries of autochthonous fish, Rutilus rutilus, which is different in some points from that obtained in the model species, Danio rerio under controlled laboratory conditions at a similar concentration level. Finally, the ability to transpose results from model to autochthonous fish was briefly discussed.

Langue : en

Revue ou ouvrage:

Intitulé de la revue ou ouvrage : Journal of Environmental Radioactivity

Abrégé ISSN : J. Environ. Radioact.

Editeur : Elsevier

N'ISBN :

N'ISSN : 0265-931X

Date de publication : 01/08/2020

Volume : 222

Numéro:

Pagination : 106365

Identifiant DOI : 10.1016/j.jenvrad.2020.106365

$\underline{\text { Informations stratégiques: }}$ 
Domaine : Secteur 6 - Recherche en Radioprotection

Axe-programme : AP 003/10 - Risques Environnementaux

Intitulé du projet : TARGET (Needs Env)

Type de mesure de protection :

Droits de diffusion:

Existence contrat particulier avec l'éditeur : NON

Conditions générales : Authors pre-print on any website, including arXiv and RePEC Author's post-print on author's personal website immediately Author's post-print on open access repository after an embargo period of between $<$ num $>12</$ num $><$ period units="month" $>$ months $<$ /period $>$ and $<$ num $>48</$ num $><$ period units="month">months</period $>$ Permitted deposit due to Funding Body, Institutional and Governmental policy or mandate, may be required to comply with embargo periods of $\langle$ num $>12</$ num $\rangle<$ period

units="month" $>$ months $</$ period $>$ to $<$ num $>48</$ num $><$ period units="month" $>$ months $</$ period $>$ Author's post-print may be used to update arXiv and RepEC Publisher's version/PDF cannot be used Must link to publisher version with DOI Author's post-print must be released with a Creative Commons Attribution Non-Commercial No Derivatives License Publisher last reviewed on 03/06/2015

Droits de diffusion / Postprint :

Type de restriction : can

Informations : Author's post-print on open access repository after an embargo period of between $<$ num $>12<$ /num $><$ period units="month" $>$ months $<$ /period $>$ and $<$ num $>48<$ /num $><$ period units="month">months</period $>$

Délai d'embargo : 6

Unité : month

Droits de diffusion / Version éditeur:

Type de restriction : cannot Informations :

Délai d'embargo : 0

Unité : 
1 Screening of potential uranium protein targets in fish ovaries after chronic

2 waterborne exposure: differences and similarities between roach and

3 zebrafish.

4

5

6

7

8

Abstract

Concentration of uranium (U), a naturally encountered radioactive element in earth's crust, can be enhanced in freshwater ecosystems $\left(\mu \mathrm{g} \cdot \mathrm{L}^{-1}-\mathrm{mg} \cdot \mathrm{L}^{-1}\right)$ due to various anthropogenic activities. The consequent aquatic organism exposure to $U$ leads to its accumulation in all organs, particularly in the gonad, and in subcellular fractions (mainly the cytosol); then it is known to affect fish at several biological levels, and more particularly, at a reproduction endpoint, with a decrease in the total number of eggs, spawn events and larvae survival. The understanding of $U$ reprotoxicity requires the fine knowledge of its speciation at molecular level, i.e., its interaction with cytosolic biomolecules. In this study, we focus on the U-protein interactions in gonads. A non-denaturating extraction protocol combined with size exclusion chromatography (SEC) allowed the separation of metal-protein complexes in ovaries of Ucontaminated wild roaches before their elemental detection (ICP MS). This enables unprecedented information to be obtained about $U$ distribution in ovaries of autochthonous fish, Rutilus rutilus, which is different in some points from that obtained in the model species, Danio rerio under controlled laboratory conditions at a similar concentration level. Finally, the ability to transpose results from model to autochthonous fish was briefly discussed.

\section{Keywords}

Uranium, speciation, ovary, biomolecules, vitellogenin, zebrafish, roach

\section{Introduction}


Concentration of uranium (U), a naturally encountered radioactive element in earth's crust, can be enhanced in freshwater ecosystems $\left(\mu \mathrm{g} \cdot \mathrm{L}^{-1}-\mathrm{mg} \cdot \mathrm{L}^{-1}\right)$ due to anthropogenic activities (Betcher et al., 1988; WHO, 2011). The consequent exposure to $U$ of living aquatic organisms has sparked studies on $U$ bioaccumulation and toxicity in diverse organisms, both fish and invertebrates (Goulet et al., 2011). It is known to affect organism growth with DNA and tissues damages and also fish reproduction with a decrease of total number of eggs, spawn events and larvae survival after waterborne chronic and environmentally relevant exposure (Barillet et al., 2011; Barillet et al., 2010; Bourrachot et al., 2014; Simon et al., 2014; Simon et al., 2018; Simon et al., 2019). Reproduction is one of the key biological functions necessary for species sustainability and fitness, and constitutes a key parameter for ecological risk assessment. Comprehensive data on reprotoxicity are therefore necessary to address the $U$ ecotoxic profile. In addition, high bioaccumulation of $U$ was recorded in gonad of zebrafish, without any elucidated mechanism for $U$ transfer to eggs (Simon et al., 2011). One can then wonder if $U$ toxicity in larvae is linked to the initial $U$ concentration in parent ovaries.

The understanding of $U$ toxicity requires a fine knowledge of its speciation at molecular level, i.e., its interaction with cytosolic biomolecules. Indeed, due to its chemical properties, uranium can interfere with essential elements of which homeostasis is regulated. Knowing the weakness of the bond between $U$ and its possible ligand groups $(O$ and $N$ atoms from biomolecules, $\mathrm{PO}_{4}{ }^{3-}$ group) (Van Horn and Huang, 2006) the identification of a U-protein edifice requires tedious non-denaturating extraction and analytical methodologies being set up, and has been discussed in numerous studies (Bucher et al., 2014a; Bucher et al., 2014b; Xu et al., 2014b).

In our previous study, we identified proteins as possible candidates for $U$ complexation in oocyte of the model fish (zebrafish, Danio rerio) exposed to $U$ under laboratory controlled 
conditions $\left(20 \mu \mathrm{g} \cdot \mathrm{L}^{-1}, 20\right.$ days, $\left.\mathrm{pH}=6.5\right)$. For this work, the combination of non-denaturating separations (Size Exclusion Chromatography (SEC) and Off Gel Electrophoresis (OGE) followed by SEC) of U-protein complexes before elemental (ICP MS) and molecular (ESI FT MS/MS) mass spectrometry detection was performed. Seven relevant proteins have been identified, revealing two main pathways of toxicity mechanisms: one specific to the reproductive organ, with target proteins (vitellogenin ( $\mathrm{Vtg}$ ) fragments and initiation factors) that are involved in oocyte development; and a second generic pathway with proteins involved in oxidative stress (initiation factor protein, glutathion transferase, glyceraldehyde phosphate dehydrogenase and a Cu-Zn superoxide dismutase) and in the oocyte structure (actin and macroglobulin) (EbLevadoux et al., 2017).

The model organism used, zebrafish (ZF), for which laboratory reproduction is easily achievable and the genome is sequenced, has been at the centre of many genomic and proteomic mechanistic studies. Previous experiments, performed under laboratory chronic exposure conditions with zebrafish, have demonstrated the $U$ tendency to bind proteins. However, the question arises of whether the gained knowledge can be extrapolated to field fish exposed to contamination over several generations. In situ experiments were performed with the roach Rutilus rutilus, an autochthonous fish from northern Europe, representative of freshwater ecosystems (Mounicou et al., 2019). Unlike the zebrafish, the roach Rutilus rutilus has a long reproduction cycle (spawning once every 2 years vs. every $2^{\text {nd }}$ to $5^{\text {th }}$ days for $Z F$, and has a rather long sexual maturity (2-4 yrs. vs. 3 months for ZF).

In our case, both species, which exhibit different reproduction cycles, have been shown to bioaccumulate $U$ in their reproductive organs at similar levels (i.e., $790-3500 \mathrm{ng} \cdot \mathrm{g}^{-1}$ dry weight (dw) for wild roaches exposed in situ vs. c.a. $960 \pm 3.5 \mathrm{ng} \cdot \mathrm{g}^{-1} \mathrm{~d}$ w zebrafish (mean values) (Eb-Levadoux et al., 2017; Mounicou et al., 2019) after a similar waterborne exposure. 
Therefore, the objective of this study was (i) to get a screening of $U$ (and other essential metals)-protein complexes in gonads of wild roaches (Rutilus rutilus) living in a $U$ contaminated pond, and of caged roaches, and (ii) compare it with those obtained in a model species, the Danio rerio under controlled laboratory conditions at similar concentration levels. Non-denaturating extraction protocol combined with size exclusion chromatography (SEC) allowed the separation of metal-protein complexes in ovaries of wild roaches living in a $U$ contaminated pond before their elemental detection (ICP MS). Finally, the ability to transpose results from model to autochthonous fish is briefly discussed.

\section{Material and methods}

\subsection{Wild and caged roach samples}

Roach fish used $(20.8 \pm 4.6 \mathrm{~g}, 12.7 \pm 1.3 \mathrm{~cm}, \mathrm{n}=12)$ in this study were sampled from the Jaladys pond, an abandoned open pit $U$ mine in the South West region of France. The $U$ concentrations (total and dissolved) and main abiotic parameters $\left(\mathrm{T}^{\circ} \mathrm{C}, \mathrm{pH}, \mathrm{O}_{2}\right)$ have been characterised in a water column (Mounicou et al., 2019). Six female roaches (numbered 62, $63,64,65,66,68)$ were sampled on the $12^{\text {th }}$ of June 2014 ([U]: $15 \mu g \cdot L^{-1}(0-2 \mathrm{~m}$ depth); [U]: 62 $\mu \mathrm{g} \cdot \mathrm{L}^{-1}\left(15 \mathrm{~m}\right.$ depth)) and another set of 6 females $(90,91,93,94,95,97)$ in $17^{\text {th }}$ July 2014 ([U]: $10 \mu \mathrm{g} . \mathrm{L}^{-1}\left(0-2 \mathrm{~m}\right.$ depth); [U]: $32 \mu \mathrm{g} \cdot \mathrm{L}^{-1}$ (15 m depth)). The concentrations given here are the total ones in which $80-90 \%$ of $U$ were dissolved (Mounicou et al., 2019). It appeared that June and July roaches cannot be considered as different from many perspectives, i.e., GSI, reproduction status, $U$ accumulation in gonads, protein and multi-elemental distribution patterns. Therefore, they have all been considered as reproduced roaches (Geraudie et al., 2010) and no distinction was made for data processing. 
purchased from a fish farm were exposed upstream of the contaminated pond $\left([\mathrm{U}]<5 \mu \mathrm{g} \cdot \mathrm{L}^{-1}\right)$ for 50 days up until the $17^{\text {th }}$ of July. Roaches were fed manually every day with commercial food.

All fish were dissected out on ice; gonads were quickly frozen in liquid nitrogen and were stored at $-80^{\circ} \mathrm{C}$ until further processing.

\subsection{Uranium total analysis, speciation and metal-protein extraction from gonads}

The procedure set-up for female zebrafish gonads was applied to all female roach gonads (Eb-Levadoux et al., 2017). Basically, for uranium total analysis, organs were digested as previously described. Then, for speciation, metal-protein complexes were extracted from fresh frozen gonad samples (c.a. $65 \pm 13 \mathrm{mg}$ ) with $1800 \mu \mathrm{L}$ of $25 \mathrm{mM}$ HEPES, $250 \mathrm{mM}$ sucrose, $\mathrm{pH} 7.4$ as buffer and using a Potter-Elvehjem homogeniser for $3 \mathrm{~min}$ in ice. Cytosolic metalprotein complexes contained in supernatant were recovered from homogenate by centrifugation ( $900 \mathrm{~g}, 20 \mathrm{~min}, 4^{\circ} \mathrm{C}$ ), and cellular debris (residue) were discarded.

\subsection{SEC-ICP SF MS analysis of metal-protein complexes}

Immediately after extraction, $80 \mu \mathrm{L}$ of the supernatant were used for SEC - ICP SF MS, as described in the work by Eb-Levadoux et al., 2017. To sum up the protocol, a Superdex 200 10/300 GL column (GE Healthcare, France) was mounted on an Agilent 1200 series liquid chromatographer equipped with a UV detector at the column outlet. The UV detector outlet was connected with PEEK tubing to the nebuliser of the ICP Sector Field Mass Spectrometer (Element XR, Thermo Fisher Scientific, Germany). Metal-protein (and others biomolecule) complexes were eluted from the column with $100 \mathrm{mM}$ ammonium acetate buffer $\mathrm{pH} 7.4$ (0.7 $\mathrm{mL} \cdot \mathrm{min}^{-1}$ ), where proteins at $280 \mathrm{~nm}$ and ${ }^{238} \mathrm{U},{ }^{31} \mathrm{P},{ }^{56} \mathrm{Fe},{ }^{64} \mathrm{Zn},{ }^{63} \mathrm{Cu}$ were successively detected 
by UV and mass spectrometry in low (for $U$ only) or medium resolution mode, respectively. The SEC column was accordingly calibrated in terms of MW and systematically cleaned after each sample analysis to remove metals bound to the stationary phase of the column.

\section{Results}

\subsection{Uranium and metal biomolecule distribution in roach gonads - Description} and relationship with ovary bioaccumulation

The biodistribution of $U$ and essential elements ( $P, F e, \mathrm{Zn}$ and $\mathrm{Cu}$ ) was studied by SECICP SF MS at the molecular level in gonads of three groups of roaches. Accumulation levels in these roach ovaries had been previously measured (Mounicou et al., 2019).

A representative elemental chromatogram in terms of protein biodistribution among wild roaches is presented in Figure 1; individual chromatograms are given in Figure $\mathbf{S 1}$ and $\mathbf{S 2 .}$ The uranium chromatogram (Fig.1A) exhibits four main MW fractions. Fraction 1 above the void of the column ( $>670 \mathrm{kDa}$ ) likely corresponds to $U$ binding protein clusters, Fraction 2 to $\mathrm{U}$ bound to proteins in the range of $89-670 \mathrm{kDa}$, and Fraction 3 to $\mathrm{U}$-protein complexes between c.a. 4 to $33 \mathrm{kDa}$. Fraction 4 is under the total volume of the column, meaning that interactions took place with the stationary phase, and that coeluted proteins are no longer separated in relation to their molecular weight. The apex of $U$ Fractions 1 and 2 matches the apex of the UV peaks at $280 \mathrm{~nm}$ (Fig 1.F), while a very small UV peak is detected at the apex of $U$ Fraction 3.

The $U$ apex in the void of the column (Fraction 1) was shared with all others elements monitored (i.e., $\mathrm{P}, \mathrm{Fe}, \mathrm{Zn}$ and $\mathrm{Cu}$ ), but this does not guarantee the binding to the same biomolecule, as no chromatographic separation takes place at that elution time. In contrast, for Fraction 4 only a small $U$ peak could be detected in the low molecular weight region (at 
$29.5 \mathrm{~min},<3 \mathrm{kDa}$ ). In this fraction, some elements monitored co-eluted as a substantial peak and with an intense UV peak.

Among the five $\mathrm{P}$ chromatographic peaks (Fig 1.B), the major one coeluting with $\mathrm{U}$ was found in the void volume of the column (Fraction 1) and to a decreasing extent in Fractions 2, and 3. The second dominant $P$ fraction was found associated with a small peak of $U$ (Fraction 4, biomolecules < $3 \mathrm{kDa}$ ). Fe chromatogram (Fig 1.C) displayed five peak apexes, while three of them are shared with four $U$ fraction apexes. The major ones are Peaks 2 and 3 , then Peak 1 Peak 4, the least intense one is Peak 5. Among the five Zn peak apexes (Fig 1.D), only the first one eluted with $U$ in Fraction 1. In the Cu chromatogram (Fig 1.E) the two most intense Cu peaks in the 40-3 kDa region didn't match the apexes of $U$, whereas in some extracts the two poorly intense Cu peaks in Fractions 1 and 2 did.

To sum-up, for July autochthonous roaches the dominant $U$ peak mainly coelutes with the $\mathrm{P}$ peak, whereas in the June ones, some Fe peaks appear coeluting with $\mathrm{P}$ and $\mathrm{U}$ (Fig S1).

To compare the uranium-protein complex distribution in the gonad of all females, the relative area (ratio of the area of the fraction to the total area of the chromatogram from 10 to $40 \mathrm{~min}$ ) was calculated for each fraction for the 12 female roach samples (Figure 2a).

First, the $U$ distribution within cytosolic biomolecules follows the same trend for all individuals with four main fractions detected (as presented in Fig1.a) and regardless of the sampling date of the roaches. For most wild individuals sampled in July and June, about 56 to $67 \%$ (average values) of $U$ is mainly associated to $3-40 \mathrm{kDa}$ proteins in Fraction 3 for roaches sampled in July and June, respectively. The uranium proportion in Fraction 2 remains constant at around 8 $9 \%$ for the two groups, whereas it ranges from $13 \%$ to $21 \%$ in Fraction 1 , which is likely to compensate for fluctuations in Fraction 3. The remaining $U(\sim 13 \%)$ consisted of a low signal 
(near baseline level) outside the defined plots. However, some important discrepancies can be observed between individuals regardless of their sample periods and their $U$ content. For example, the two roaches labelled 64 and 65 had about $90 \%$ of the $U$ in Fraction 3, in contrast with some individuals (i.e., 90 and 93) showing a fairly equal distribution between Fractions 1 and 3. Additionally, this $U$ peak intensity of individuals numbered 64 and 65 was about 50 -fold higher than the average peak intensity for fish of the other group sampled in July (Fig. S1).

For upstream caged roaches, distribution is slightly different with a main Fraction 1 having $45 \%$ of $U$, Fractions 2 and 3 with around $20 \%$ of $U$, and finally Fraction 4 with $15 \%$.

To prospect for a link between one of the cytosolic fractions and the bioaccumulation of $U$ in ovaries of both wild and caged roaches, Figures $\mathbf{2} \mathbf{b}$ and $\mathbf{S 3}$ (for individuals with extreme $\mathrm{U}$ burden values, i.e., ten times lower $(68,65,97)$ or up to five times higher $(90,95)$ than the average) show the relation between the $U$ distribution in each fraction and the $U$ concentration in the organ. A positive linear relationship between the distribution in $\mathrm{F} 3$ and the $U$ concentration in the organ can be established in Figure $2 b\left(R^{2}>0.90\right)$, in which extreme values of $U$ content were excluded. No linear relationship was observed for individuals with low or high $\mathrm{U}$ accumulation levels (Figure S3). In addition, a negative linear relationship was also established between the distribution in $\mathrm{F} 1$, in $\mathrm{F} 2$ and the $\mathrm{U}$ concentration in the organ (with $R^{2}>0.72$ and $R^{2}>0.95$, respectively).

\subsection{Metal-protein complexes cytosolic distribution: roach vs. zebrafish}

The distributions of uranium and other endogenous elements in cytosol of zebrafish ovaries have already been described in our previous work (Eb-Levadoux et al., 2017). They are compared with those acquired for wild and caged roaches in this study (Figure 3). A clear difference can be observed in the $U$ chromatograms (Fig. 3A), not only in terms of signal 
intensity (left $y$-scale for zebrafish, right one for roaches) but also in terms of $U$ distribution along cytosolic biomolecules. Indeed, a c.a. 50-fold signal difference and a clear elution time shift could be noticed between the major $U$ peak of each chromatogram at 22.8 min (equivalent to $21 \mathrm{kDa}$ at peak apex, fraction MW range: $54-8 \mathrm{kDa}$ ) and $24.6 \mathrm{~min}$ (equivalent to $11 \mathrm{kDa}$ at peak apex, fraction MW range: $21-4 \mathrm{kDa}$ ) for the zebrafish and roach cytosols, respectively. It is also important to note the distinct $U$ relative proportion between the two fish, with a high $U$ proportion (around $90 \%$ ) at 22.8 min peak apex and consistent for all zebrafish females analysed (Eb-Levadoux et al., 2017), contrary to the more variable but homogeneous $\mathrm{U}$ distribution among F1 and F3 proteins of female roaches.

Other endogenous elements (Fig3. B-E), P, Fe, Cu, Zn exhibited a similar biomolecular distribution in zebrafish and roach cytosols, except that the abundance of each element differed according to the fish species investigated. However, few noticeable differences are observed. Indeed, the P pattern is slightly different in the 4-89kDa region where two peaks (at 18 and $24.6 \mathrm{~min}$ ) are eluted in roaches, compared to only one, more intense, (at $22.8 \mathrm{~min}$ ) in reproduced zebrafish (Fig3.B). The other noticeable difference is the appearance of a $\mathrm{Zn}$ peak at $22.8 \mathrm{~min}$, with an increase in the Fe level at the same retention time for the roach cytosol (Fig3.D). This Zn-containing protein fraction was absent in the zebrafish cytosol chromatogram, where $90 \%$ of $U$ is found. Finally, UV-protein elution profiles (Fig3. F) were consistent between the two fish species according to the $280 \mathrm{~nm}$ UV detection, but the relative proportion of the protein fraction was different between species. It is noteworthy that, to the same extent for the two fish species, the $280 \mathrm{~nm}$ UV signal is close to the baseline level in Fraction 3 where $U$ is predominant.

\subsection{Uranium-phosphorus coelution in gonad cytosol: roach vs. zebrafish}


zebrafish gonads, showed multiple shared coelutions between $U$ and $P$. Therefore, the relationship between the $\mathrm{P}$ and $\mathrm{U}$ distributions in the different fractions was studied in cytosols of female roaches (both wild and caged) and female reproduced zebrafish (reproduced zebrafish were chosen to be homogenous with the "reproduced" status of roaches in our study and to compare oocytes at similar developmental status in both fish).

Figure 4 shows this U/P distribution relationship in zebrafish (left panels) and in roaches (right panels).

Regardless of the fish species and the $U$ accumulation levels in the whole organ and the $U$ content in the main F3 fraction, the $U$ percentage in this main fraction is linearly correlated to the P percentage (Figure 4C). The slope is similar, i.e., 2.44 and 2.93 for zebrafish and roaches, respectively, with $R^{2}=0.8$ as the minimum value. For upstream caged roaches, the sample size is too low to conclude on the trend. Likewise but with a slope ten times lower, the F4 fraction (Figure 4D), is linearly linked to the P percentage for most roach individuals (both wild and caged ones). In Fraction 2 (Figure 4B), the relationship between $\mathrm{U} \%$ and $\mathrm{P} \%$ is not linear whatever the group of fish studied. In Fraction 1 (Figure 4A) a linear relationship with similar slopes is established for wild and caged roaches and not for zebrafish, for which the $U$ proportion in this fraction is 4-fold less than for roaches.

\section{Discussion}

The reproduction endpoint is an ecologically relevant parameter that directly influences population dynamics. Understanding the accumulation mechanism of $U$ in ovaries is therefore the first step to determine its observed reprotoxicity profile. Furthermore, elemental speciation is a key parameter to elucidate the toxicity of an element (Sanz-Medel, 
1998). Our first works focused on Danio rerio and led to the identification of candidate proteins for complexation with $U$. To complete the $U$ profile, this study focuses on uranium speciation in wild fish ovaries in order to evaluate uranium, endogenous elements and protein coelution. The second objective was to compare this $U$ distribution with that found in the zebrafish model, in order to assess the robustness of the extrapolation methodology from model to wild contaminated fish.

\subsection{Roach versus zebrafish: evidence for different $U$ speciation}

In gonads of roaches, $U$ was distributed among four biomolecule fractions for all individuals investigated. Uranium accumulation levels and $U$ fraction distributions seem to be closely linked, except for Fraction 4. However, some differences were noticed in the relative distribution and the absolute intensity of fractions, without any obvious link with $U$ accumulation levels in the gonads. These results were compared with SEC-ICP SF MS results of U-exposed zebrafish (Eb-levadoux et al 2017). Despite similar accumulation levels in ovaries of both species, the first difference observed is the consistency of the $\mathrm{U}$-biomolecule relative distribution in zebrafish cytosol against the variability of this distribution in the present study. This can partially reflect the different exposure conditions: (i) the zebrafish exposure under well-controlled conditions in the laboratory, ensuring a constant $U$ speciation in water, and (ii) the in situ exposure of roaches, where the $\mathrm{U}$ concentration $\left(10\right.$ to $62 \mu \mathrm{g} . \mathrm{L}^{-1}$ ) and the $\mathrm{pH}$ (around 6.5 (0-2 m depth); 5.5 (June, $15 \mathrm{~m}$ depth); 6.8 (July, $15 \mathrm{~m}$ depth) (Mounicou et al., 2019) vary in the water column and throughout the season (variable diet), thus impacting $U$ speciation in water, $U$ bioavailability and $U$ accumulation. This reproducibility observed in zebrafish compared to roaches can also partially arise from the reproduction cycle of these two fish; the roach population is more heterogeneous in age and more likely to be dependent on its 
environment for its reproduction (variable reproduction status with variable phosphorylated

258

259

260

261 amino acid content in ovary proteins), whereas zebrafish are more homogeneous in age and synchronous in their reproduction (Gerbron et al., 2014; Lawrence, 2007; Simon et al., 2014). Thus, the distribution pattern in different fish gonads is not linked to the accumulation level only.

In addition, the investigation of uranium and endogenous element distributions among cytosolic biomolecules in roach gonads has shown the co-elution of uranium with some endogenous elements-containing proteins, mainly phosphorus, confirming once more the known affinity of uranyl ions with phosphorylated proteins, as already reported (Basset et al., 2008; Bucher et al., 2014b; Eb-Levadoux et al., 2017; Huynh et al., 2016; Safi et al., 2013). Therefore, P-containing biomolecules seem to play an important role in $\mathrm{U}$ trafficking in gonad cytosol. However, uranyl appears to be somehow specific to some phosphorus-containing proteins, as it doesn't coelute homogeneously with $\mathrm{P}$ but preferentially in Fraction 3, where the $\mathrm{P}$ signal is the least intense. Interestingly, the same molecular weight range for the main fraction and the linearity of the $P$ and $U$ percentage relationship in this main fraction were also found after zebrafish exposure (Eb-levadoux et al 2017). According to the $P$ content and to the MW elution range of this fraction $(40-3 \mathrm{kDa}), U$ could be expected to bind phosphorylated fragments of vitellogenin $(\mathrm{Vtg})$. In addition, the relationship between $U$ and $\mathrm{P}$ in Fraction 2 (670-92 kDa) suggested the presence in roach ovaries of uranium binding with a high molecular weight protein complex between 320 and $610 \mathrm{kDa}$ that could be the entire Vtg (Hara et al., 2016; Wallace and Selman, 1985).

Vtg is the most abundant glycolipophosphoprotein of oocytes (Garnayak et al., 2013), with a high MW around 400kDa (Hara et al., 2016; Wallace and Selman, 1985). It needs to 
undergo enzymatic degradations, i.e., leading to lipovitellin and phosvitin, in order to be used

281

282

283

284

285 as vitellin reserve by the future progeny (Gerbron et al., 2014; Örn et al., 2003). Thus, the presence of the entire $\mathrm{Vtg}$ in ovaries is controversial. Often described as immediately processed after its entry into the ovary (Amano et al., 2008), it has already been detected in ovaries of the fish Tanichthys albonube (Zhong et al., 2014). According to the species, Vtg (MW, enzymatic products) and its enzymatic degradation can be different (Yilmaz et al., 2016). Vtgs of zebrafish have three main domains, the heavy chain lipovitellin (120 kDa), the light lipovitellin (30-35 kDa) and phosvitin (6 kDa) chains, leading to several combinations for the by-products after enzymatic degradation. For instance, these include lipovitellin-phosvitin complexes (Byrne et al., 1989). The hypothesis of $U$ complexation by Vtg (more particularly by a highly phosphorylated phosphvitin complex) in ovaries has already been made after zebrafish exposure (Eb-levadoux et al 2017), especially as zebrafish exhibit a decrease in the $\mathrm{U}$ accumulation in ovaries after spawning and an $\mathrm{U}$ accumulation in eggs. Unfortunately, the phosvitin domain, which is more or less phosphorylated depending on the species, cannot be identified by mass spectrometry due to its chemical composition (Samaraweera et al., 2014). In our study, the molecular weight $(\mathrm{MW})$ of the biomolecule fraction binding $U$ in roaches ( 11 $\mathrm{kDa}$ ) and the $\mathrm{P}$ content signal in this medium $\mathrm{MW}$ range are different from those in zebrafish ( $21 \mathrm{kDa}$ and high $\mathrm{P}$ content). In contrast, no MW difference was noticed for the other endogenous elements in this region, except for $\mathrm{Zn}$.

A search on the UniProtKB engine revealed the identification in roaches ( $R$. rutilus), of a 237residue vitellogenin fragment (c.a. $27.7 \mathrm{kDa}, 3 \%$ phosphorylated serines, https://www.uniprot.org/uniprot/C6ZNM7) and a 103-residue vitellogenin fragment (11.2 $\mathrm{kDa}, 2.9 \%$ phosphorylated serine, https://www.uniprot.org/uniprot/A0A221LCK1) against $20 \%$ and up to $40 \%$ of the phosphorylated serine content in the phosvitin domain of the most 

lipovitellin derivatives are likely to contain the phosphorylated phosvitin domain, taking into account the P signal detected at that elution time (c.a. $22.8 \mathrm{~min}$, c.a. $21 \mathrm{kDa}$ ). In contrast, the supposed lipovitellin fragment eluting later for the roach gonad cytosol, seemed to be phosvitinless, or at least a fragment containing phosvitin with lower phosphorylated serine residue content because of the low intensity $\mathrm{P}$ peak co-eluting.

As phosvitin is also known to chelate cations and particularly Fe, this might explain the small Fe peak tailing coeluting with $U$ and $P$ in the roach lipovitellin $M W$ region. Interestingly, in roach oocyte, $\mathrm{Fe}, \mathrm{Zn}$ and $\mathrm{Cu}$ co-elution ( $22.8 \mathrm{~min}, \mathrm{U}$ free and very low $\mathrm{P}$ content) perfectly fits the elution time of $\mathrm{U}$ - light lipovitellin fragments ( $\mathrm{Zn}$ free, but $\mathrm{Fe}, \mathrm{Cu}$ and quite high $\mathrm{P}$ content) for zebrafish oocyte. This leads us to assume either the presence in roach oocyte of metalloprotein(s) other than lipovitellin fragments, such as transferrin, $\mathrm{Cu}-\mathrm{Zn} \mathrm{SOD,} \mathrm{a} \mathrm{subunit}$ of haemoglobin, the latter two already having been identified in zebrafish oocyte (EbLevadoux et al., 2017; Xu et al., 2014a, b), or a lipovitellin fragment with a very low absolute phosphorylated serine content so $U$ binding cannot be observed, leaving the binding sites free for complexation with other metals, such as $\mathrm{Fe}, \mathrm{Zn}$ and $\mathrm{Cu}$.

To conclude, from several points Vtg or Vtg maturation products can be considered as good candidates for U-binding in the ovaries of these two fish. The co-elution with Fe supports this hypothesis, as Vtg is also known to bind Fe and other metals. Unfortunately, the molecular identification could not be done. The roughly homogeneous distribution of uranium in roaches, in contrast to the single main fraction in zebrafish, and its relationship with $\mathrm{P}$ content, 
distributions. Indeed, zebrafish continuously produce mature oocytes, with maturation products such as phosphorylated $V \operatorname{tg}$ fragments ( $~ 90 \%$ of the uranium accumulated in the gonad is found in the $21 \mathrm{kDa}$ fraction), compared to once a year for roaches.

Interestingly, high levels of $U$ accumulation (x3-6 compared to ovary) were also observed in the liver of roaches (Mounicou et al 2019), in which Vtg is produced; U speciation in liver should be interesting to perform, in order to explain the origin of $U$ transport in an ovary.

\subsection{U containing protein: a possible marker of biological effects on reproduction?}

Up to now, the level of accumulation (from a threshold value) in a whole organ could be considered as a predictive marker of deleterious biological effects. The evaluation of toxic effects, through the assessment of speciation and the functional disturbance of U-bound proteins, requires specific approaches, as proposed in this study. This first speciation study on wild roaches shows high variation in protein profiles and essential element levels between individuals, and indicates that $\mathrm{U}$ could be linked to $\mathrm{Vtg}$ or derivatives. If so, like in zebrafish, U-Vtg will be rapidly digested by future embryos leading to $U$ internalisation in early life stages and finally to toxic effects (Bourrachot et al., 2008). This encourages us to study the reprotoxicity effect of $U$ in the early stages of this wild species. This first study also tends to show that the reproduction status and the protein content in ovaries play a key role in the uranium distribution. Therefore, for fish with reproduction cycle such as roaches, this study underlines the need to consider all peaks as exposure markers in a risk assessment context. So, at this step of knowledge, this is roughly equivalent as considering the total uranium amount in the gonad what is not fully satisfying. Thus, it would be necessary to better characterise uranium complexes from each fraction with target protein identification and 
investigate their consequences on reprotoxicity to assess the relevance of each fraction analysis and focus on the best one.

\section{Conclusions}

Size exclusion chromatography coupled to ICP MS in conjunction with an appropriate nondenaturing sample preparation and separation protocol allowed the monitoring of U-protein complexes in gonads of wild female roaches from a contaminated pond. With regard to $P$ monitoring and other endogenous elements ( $\mathrm{Fe}, \mathrm{Zn}$ and $\mathrm{Cu}$ ), as well as to previous studies on a sequenced model of fish, hypotheses regarding the protein binding $U$ can be put forward; vitellogenin fragments including its maturation products are expected to bind $U$. However, compared to the model organism that we investigated earlier, clear differences could be demonstrated in the distribution of $U$ complexes. The reproduction status and different vitellogenin forms can most likely be the origin. Finally, it is noteworthy to underline that any of these hypothesised proteins found in $U$ containing-fractions were not formally identified by mass spectrometry; therefore, further more advanced analysis would be necessary for deeper understanding. This study confirms the contribution of speciation studies in understanding toxic mechanisms and the contribution of fish sequenced models benefiting from efficient molecular tools.

\section{Acknowledgments}

The authors acknowledge the NEEDS-Environment program for funding the TARGETS project supporting this work, as well as Antoine Le Guernic and, more particularly, Henri Pigeyre for their help and technical help during in situ experiments.

\section{Figure captions}


Figure 1. SEC-ICP SF MS distribution of ${ }^{238} \mathrm{U}$ (Panel A), ${ }^{31} \mathrm{P}$ (Panel B), ${ }^{56} \mathrm{Fe}$ (Panel C), ${ }^{64} \mathrm{Zn}$ (Panel D), ${ }^{63} \mathrm{Cu}$ (Panel E), proteins (Panel F) in an ovary cytosol extract of wild $R$. rutilus (G63) sampled from the Jaladys pond.

Figure 2. (A) Relative $U$ distribution (\%) in each SEC fraction (F1-F4) of roach cytosolic extracts. For each fraction the dashed line delimitates the different experimental conditions (Wild June, Wild July and Upstream caged); (B) Correlation of $U$ percentage in each SEC fraction and ponderal $U$ (ng.g-1) in roach gonads; data from upstream caged roaches are in the circle. Among the fourteen fish, five individuals with low or high $U$ accumulation levels did not exhibit linear relationship: they were plotted in Figure S3.

Figure 3. Comparison of SEC-ICP SF MS chromatograms of ${ }^{238} \mathrm{U}$ (Panel A), ${ }^{31} \mathrm{P}$ (Panel B), ${ }^{56} \mathrm{Fe}$ (Panel C), ${ }^{64} \mathrm{Zn}$ (Panel D), ${ }^{63} \mathrm{Cu}$ (Panel E) and proteins (Panel F) in an ovary cytosolic extract from female wild roach (G63) sampled from the Jaladys pond, and, of an exposed reproduced female zebrafish (ZF32) under laboratory conditions ([U]: $20 \mu \mathrm{g} . \mathrm{L}^{-1}, 20$ days). F1 to F4 and F1' to F4' are the MW fractions defined for roach and zebrafish samples respectively.

Figure 4. Relashionship between U\% and P\% in each defined SEC fraction for zebrafish (left panels) and for roach samples (right panels); data coming from autochthonous or caged roaches are identified in each panel. A, B, C, D are the corresponding panels for Fraction F1/F1', F2/F2', F3/F3', F4/F4', respectively. Indicative molecular weight ranges are given for each fraction. 
392

Amano, H., Fujita, T., Hiramatsu, N., Kagawa, H., Matsubara, T., Sullivan, C.V., Hara, A., 2008. Multiple vitellogenin-derived yolk proteins in gray mullet (Mugil cephalus): Disparate proteolytic patterns associated with ovarian follicle maturation. Molecular Reproduction and Development 75, 1307-1317.

Barillet, S., Adam-Guillermin, C., Palluel, O., Porcher, J.M., Devaux, A., 2011. Uranium bioaccumulation and biological disorders induced in zebrafish (Danio rerio) after a depleted uranium waterborne exposure. Environmental Pollution 159, 495-502.

Barillet, S., Larno, V., Floriani, M., Devaux, A., Adam-Guillermin, C., 2010. Ultrastructural effects on gill, muscle, and gonadal tissues induced in zebrafish (Danio rerio) by a waterborne uranium exposure. Aquatic Toxicology 100, 295-302.

Basset, C., Dedieu, A., Guérin, P., Quéméneur, E., Meyer, D., Vidaud, C., 2008. Specific capture of uranyl protein targets by metal affinity chromatography. Journal of Chromatography $A$ $1185,233-240$.

Betcher, R.N., Gascoyne, M., Brown, D., 1988. Uranium in groundwaters of southeastern Manitoba, Canada. Canadian Journal of Earth Sciences 25, 2089-2103.

Bourrachot, S., Brion, F., Pereira, S., Floriani, M., Camilleri, V., Cavalié, I., Palluel, O., AdamGuillermin, C., 2014. Effects of depleted uranium on the reproductive success and F1 generation survival of zebrafish (Danio rerio). Aquatic Toxicology 154, 1-11.

Bourrachot, S., Simon, O., Gilbin, R., 2008. The effects of waterborne uranium on the hatching success, development, and survival of early life stages of zebrafish (Danio rerio). Aquatic Toxicology 90, 29-36.

Bucher, G., Frelon, S., Simon, O., Lobinski, R., Mounicou, S., 2014a. Development of nondenaturing off-gel isoelectric focusing for the separation of uranium-protein complexes in fish. Analytical and Bioanalytical Chemistry 406, 3517-3520.

Bucher, G., Mounicou, S., Simon, O., Floriani, M., Lobinski, R., Frelon, S., 2014b. Different uranium distribution patterns in cytosolic protein pool of zebrafish gills after chronic and acute waterborne exposures. Chemosphere 111, 412-417. 
Byrne, B.M., Gruber, M., Ab, G., 1989. The evolution of egg yolk proteins. Progress in Biophysics and Molecular Biology 53, 33-69.

421 Eb-Levadoux, Y., Frelon, S., Simon, O., Arnaudguilhem, C., Lobinski, R., Mounicou, S., 2017. In 422 vivo identification of potential uranium protein targets in zebrafish ovaries after chronic waterborne exposure. Metallomics 9, 525-534.

Garnayak, S.K., Mohanty, J., Rao, T.V., Sahoo, S.K., Sahoo, P.K., 2013. Vitellogenin in Asian catfish, Clarias batrachus: Purification, partial characterization and quantification during the reproductive cycle by ELISA. Aquaculture 392-395, 148-155.

Geraudie, P., Gerbron, M., Hill, E., Minier, C., 2010. Roach (Rutilus rutilus) reproductive cycle: A study of biochemical and histological parameters in a low contaminated site. Fish Physiology and Biochemistry 36, 767-777.

Gerbron, M., Geraudie, P., Fernandes, D., Rotchell, J.M., Porte, C., Minier, C., 2014. Evidence of altered fertility in female roach (Rutilus rutilus) from the River Seine (France). Environmental Pollution 191, 58-62.

Goulet, R.R., Fortin, C., Spry, D.J., 2011. Uranium, Fish Physiology. 31, pp. 391-428.

Hara, A., Hiramatsu, N., Fujita, T., 2016. Vitellogenesis and choriogenesis in fishes. Fisheries Science 82, 187-202.

Hu, L., Sun, C., Luan, J., Lu, L., Zhang, S., 2015. Zebrafish phosvitin is an antioxidant with noncytotoxic activity. Acta Biochimica et Biophysica Sinica 47, 349-354.

Huynh, T.N.S., Vidaud, C., Hagège, A., 2016. Investigation of uranium interactions with calcium phosphate-binding proteins using ICP/MS and CE-ICP/MS. Metallomics 8, 1185-1192. 20.

442 Mounicou, S., Frelon, S., Le Guernic, A., Eb-Levadoux, Y., Camilleri, V., Février, L., Pierrisnard, 443 S., Carasco, L., Gilbin, R., Mahé, K., Tabouret, H., Bareille, G., Simon, O., 2019. Use of fish 444 otoliths as a temporal biomarker of field uranium exposure. Science of the Total Environment 445 $690,511-521$. 
Örn, S., Holbech, H., Madsen, T.H., Norrgren, L., Petersen, G.I., 2003. Gonad development and vitellogenin production in zebrafish (Danio rerio) exposed to ethinylestradiol and methyltestosterone. Aquatic Toxicology 65, 397-411.

Safi, S., Creff, G., Jeanson, A., Qi, L., Basset, C., Roques, J., Solari, P.L., Simoni, E., Vidaud, C., Den Auwer, C., 2013. Osteopontin: A uranium phosphorylated binding-site characterization. Chemistry - A European Journal 19, 11261-11269.

Samaraweera, H., Moon, S.H., Lee, E.J., Grant, J., Fouks, J., Choi, I., Suh, J.W., Ahn, D.U., 2014. Characterisation of phosvitin phosphopeptides using MALDI-TOF mass spectrometry. Food Chemistry 165, 98-103.

Sanz-Medel, A., 1998. Trace element analytical speciation in biological systems: Importance, challenges and trends. Spectrochimica acta, Part B: Atomic spectroscopy 53, 197-211.

Simon, O., Floc'h, E., Geffroy, B., Frelon, S., 2014. Exploring the value of fish bioassays for evaluating uranium toxicity: Effects of uranium on the reproductive performance of Danio rerio. Environmental Toxicology and Chemistry 33, 1817-1824.

Simon, O., Floriani, M., Cavalie, I., Camilleri, V., Adam, C., Gilbin, R., Garnier-Laplace, J., 2011. Internal distribution of uranium and associated genotoxic damages in the chronically exposed bivalve Corbicula fluminea. Journal of Environmental Radioactivity 102, 766-773.

Simon, O., Gagnaire, B., Camilleri, V., Cavalié, I., Floriani, M., Adam-Guillermin, C., 2018. Toxicokinetic and toxicodynamic of depleted uranium in the zebrafish, Danio rerio. Aquatic Toxicology 197, 9-18.

Simon, O., Gagnaire, B., Sommard, V., Pierrisnard, S., Camilleri, V., Carasco, L., Gilbin, R., Frelon, S., 2019. Uranium transfer and accumulation in organs of Danio rerio after waterborne exposure alone or combined with diet-borne exposure. Environmental Toxicology and Chemistry 38, 90-98.

Van Horn, J.D., Huang, H., 2006. Uranium(VI) bio-coordination chemistry from biochemical, solution and protein structural data. Coordination Chemistry Reviews 250, 765-775.

Wallace, R.A., Selman, K., 1985. Major protein changes during vitellogenesis and maturation of Fundulus oocytes. Developmental Biology 110, 492-498.

WHO, 2011. Uranium in Drinking-water, WHO/SDE/WSH/03.04/118/Rev/1 
475 Xu, M., Frelon, S., Simon, O., Lobinski, R., Mounicou, S., 2014a. Development of a non476 denaturing 2D gel electrophoresis protocol for screening in vivo uranium-protein targets in 477 Procambarus clarkii with laser ablation ICP MS followed by protein identification by HPLC478 Orbitrap MS. Talanta 128, 187-195.

479 Xu, M., Frelon, S., Simon, O., Lobinski, R., Mounicou, S., 2014b. Non-denaturating isoelectric 480 focusing gel electrophoresis for uranium-protein complexes quantitative analysis with LA-ICP 481 MS. Analytical and Bioanalytical Chemistry 406, 1063-1072.

482 Yilmaz, O., Prat, F., Ibáñez, A.J., Köksoy, S., Amano, H., Sullivan, C.V., 2016. Multiple 483 vitellogenins and product yolk proteins in European sea bass (Dicentrarchus labrax): Molecular 484 characterization, quantification in plasma, liver and ovary, and maturational proteolysis. 485 Comparative Biochemistry and Physiology Part - B: Biochemistry and Molecular Biology 194$486195,71-86$.

487 Zhong, L., Yuan, L., Rao, Y., Li, Z., Zhang, X., Liao, T., Xu, Y., Dai, H., 2014. Distribution of 488 vitellogenin in zebrafish (Danio rerio) tissues for biomarker analysis. Aquatic Toxicology 149, $489 \quad 1-7$. 